\title{
Intergroup Contact as a Potential Path to Neutralize the Detrimental Effect of National Identification on Xenophobia in Germany
}

\author{
Petia Genkova ${ }^{1}$ (D) Christoph Daniel Schaefer ${ }^{1} \cdot$ Simone Karch $^{2}$
}

Accepted: 12 November 2021 /Published online: 29 November 2021

(c) The Author(s) 2021

\begin{abstract}
Proceeding globalization and the increase in global mobility entail that a growing proportion of people in economically developed countries have a migration background, so that cultural diversity has become an integral characteristic of many societies. Consequently, national identifications and attitudes towards immigrants are gaining importance in both international and intra-societal contexts. Previous studies revealed that in some countries, including Germany, national identification is associated with negative attitudes towards outgroups. In the present article, the interplay between national identification and intergroup contact is analyzed, with xenophobia as the criterion. The study is based on a cross-sectional survey amongst members of the majority population in Germany. It was predicted and found that the association between national identification and xenophobia is moderated by intergroup contact. There was only an association between national identification and xenophobia in participants with below-average or average levels of contact, whilst for those with above-average levels of contact, there was no significant association. Thus, the results point to the importance of contact experiences as a path to neutralize the effects of national identification on xenophobia, possibly by assisting in a redefinition of national belonging.
\end{abstract}

Keywords National identification - Xenophobia · Prejudice against immigrants · Contact hypothesis $\cdot$ Neutralizing effect of contact

Petia Genkova

p.genkova@hs-osnabrueck.de

1 Department of Economic and Social Sciences, University of Applied Sciences Osnabrück, Osnabrück, Germany

2 University of Passau, Passau, Germany 


\section{Introduction}

Globalization, technological progress, and political processes entail that global mobility is increasing. The consequences of these developments include an increase of the proportion of immigrants in many economically developed countries. According to the German Federal Statistical Office, about a quarter of the German population (26\%) had an immigration background in 2019 (i.e. they are immigrants themselves or are descendants of immigrants) (Statistisches Bundesamt, 2020).

Sixty-four percent of those had immigrated themselves and 52\% had German citizenship (Bundesamt für Migration und Flüchtlinge, 2020). For 35\% of people with an immigration background living in Germany, the country of birth or their parents' country of birth was another country of the EU; for 30\%, their or their parents' country of birth was another European (non-EU) country (13\%Turkey; 7\% Russian federation); for 22\%, it was an Asian country; for 5\%, it was an African country (other: 3\%; unknown: 6\%; Bundesamt für Migration und Flüchtlinge, 2020). Thirty-six percent of those who immigrated themselves arrived in Germany less than 10 years ago (Bundesamt für Migration und Flüchtlinge, 2020). Similar to the situation in many other countries, debates on immigration have tended to politically polarize the German majority population. Some parts of the population have been reacting to a rising number of immigrants with xenophobia, that is with rejection of the cultural, linguistic, and/or "ethnic" otherness (Decker et al., 2018).

Xenophobia is a relevant problem for societies, undermining societal cohesion and productive potential. Xenophobia affects societal cohesion by reducing societal identification of those confronted with xenophobia. In the context of Germany, it was found, for example that the extent to which Muslims or people with a Turkish migration background experience rejection is associated with less societal identification (Holtz et al., 2013; Martinovic \& Verkuyten, 2012; Schaefer \& Simon, 2019). Additionally, xenophobia has detrimental effects on the health of the members of discriminated communities (Suleman et al., 2018).

Previous studies have found an association between national identification and xenophobia (Billiet et al., 2003; Maddens et al., 2000; Pehrson et al., 2009; Triandafyllidou, 2000; Weiss, 2003). These results are compatible with social identity theory (Tajfel \& Turner, 1979) and self-categorization theory (Turner, 1987). According to the social identity theory, group members strive to be positively distinctive from other groups, by favouring their own group at the expense of other groups, with the aim of a positive self-worth (Tajfel \& Turner, 1979). Self-categorization theory (Turner, 1987) as the more encompassing theory, stipulates that ingroup liking depends on the degree to which group members are seen to correspond to the ideal self and to the prototype of positively evaluated ingroups. Analogously, outgroup members are devalued to the extent that the outgroup or its prototype is perceived as deviating from the prototype of an appreciated ingroup.

It has been observed that national identification of majority members is associated with prejudice against immigrants in some countries (Pehrson et al., 2009). As a moderating factor on the relationship between national identification and anti-immigrant prejudice, it was examined on which criteria inhabitants based their definition of national belonging (Pehrson et al., 2009). In particular, it was investigated whether belonging 
was defined as depending on language or on citizenship. The authors regarded language as indicating a cultural definition of national belonging, while citizenship was viewed as an indication of a civic definition. The relationship between national identification and prejudice was revealed to be stronger for inhabitants defining national belonging as being based on language. While this result can be interpreted as indicating that a cultural definition of belongingness is less open to integrating immigrants than a civic definition, it is debatable whether language is a valid marker of an exclusionary cultural view on national belonging, since the acquisition of a country's language is, at least in principle, open to people from various cultural backgrounds.

However, an informative supplement to this result is constituted by a study which examined various indicators of an "ethnic", essentialist definition of national belonging (Pehrson et al., 2011). These items aimed to assess to what extent participants viewed nationality as being determined by descent, and thus as being clearly distinguishable from other national groups. Only among individuals with such an essentialist definition of national belongingness, a relationship between national identification and a rejection of immigrants was found. Thus, an exclusionary conception of nationhood leads to a devaluation of immigrants with a diverging background when national identification is high.

A result pointing in a similar direction was obtained by studies which analyzed variations within nations (Bauer \& Hannover, 2020). It was demonstrated that viewing the criteria which define national belonging as fixed (versus malleable) led to a sharper perceived divide between ingroup and outgroup as well as to an increase in prejudice against immigrants. Thus, the understanding or definition of society appears to influence both the degree of prejudice and the strength of the association between national identification and prejudice.

These results are in accordance with self-categorization theory (Turner, 1987). A perspective that defines the criteria of national belonging as fixed and essentialist, notably by basing the national belonging on descent, can mark immigrants as incompatible with the national prototype. To the extent that the national group constitutes an appreciated ingroup, the deviation of immigrants from the national prototype constitutes a deviation from the ideal self, which, according to self-categorization theory, leads to dislike. Thus, an essentialist conception of the ingroup and an appreciation of the national ingroup are both theoretically and empirically related to prejudice against immigrants.

Fitting to this theoretical outlook is also the role of symbolic threats indicated by intergroup threat theory (Stephan \& Stephan, 2013). Symbolic threats are conceptualized as perceived threats to the ingroup's system of values. When an appreciated national ingroup is defined as being based on a fixed system of values that is distinguished from the values of immigrants, a high number of immigrants can be perceived as potentially diluting the appreciated ingroup prototype. Especially when national groups and their values are perceived, in an essential way, as fixed, the appreciation of the ingroup should be associated with a devaluation of immigrants that are perceived as different and as diluting the perceived essence of the group, either on the basis of assumed cultural differences (as a form of symbolic threat) or on the basis of assumed biological or "ethnic" differences (when a community of descent is assumed). Another variety of a perceived threat to an appreciated ingroup is constituted by threats to an ingroup's well-being, power, or even existence, termed "realistic threats", in the taxonomy of Stephan and Stephan (2013). When viewing 
the ingroup in essentialist cultural or ethnic terms, the group borders should be perceived as sharper, so that the perception of immigrants as being a source of competition for material resources and wealth might increase. Thus, an essentialist view of a national ingroup in combination with a high national group identification might increase the likelihood of xenophobia also via this route.

Since the effects of national identification depend on the understanding of the nation as essentialist versus open, it is of special relevance for intergroup relations to identify factors affecting these national self-definitions. Intergroup contact has been demonstrated to affect both the perception of group boundaries (Brown, 2002; Dovidio et al., 2007) and intergroup attitudes (Pettigrew \& Tropp, 2006). The positive effect of contact on intergroup relations has also been indicated for the relations between majority and minorities within societies. Contact between members of the majority population and members of minorities was observed to reduce prejudice (Binder et al., 2009; Pettigrew, 1997).

It is important to note that the contact hypothesis originally formulated by Allport (1954) does not state that any type of contact leads to an improvement of attitudes. Instead, Allport (1954) specified that the contact has to adhere to four conditions in order to precipitate its positive effects: members from the two groups should have equal status in the interaction, share common goals, cooperate to achieve these common goals, and experience that the contact is supported by an authority or salient values. A meta-analysis found that direct contact typically improves intergroup attitudes, even when Allport's contact conditions are not met, while the fulfilment of these conditions increases the degree of contact's positive effect (Pettigrew \& Tropp, 2006). This result does not, however, imply that superficial contact is sufficient for the improvement of attitudes. Erasmus (2010), for example refers to instances in South Africa in which exclusion and conflict between groups have persisted despite intergroup contact. Amongst the examples on which Erasmus (2010) draws is a desegregated beach (Durrheim \& Dixon, 2005) or a medical school with black and white students (Erasmus \& De Wet, 2003/2011). In the context of the desegregated beach, the study authors report that nearly all of the attending groups were "racially" homogeneous (Durrheim \& Dixon, 2005). Also in the context of the medical school, students reportedly remained in racially homogenous groups even in classrooms (Erasmus \& De Wet, 2003/2011). These results are in line with earlier indications that proximity does not guarantee positive interaction or mitigating effects on prejudice (Pettigrew \& Tropp, 2006). Importantly, Pettigrew and Tropp (2006) did only include studies in their meta-analysis in which there was direct intergroup interaction between groups. It is also likely that conditions of underlying inequality which are entrenched in the respective national or local history and structures further hamper positive effects of contact. In the study of the medical school in South Africa, for example several black students reported marginality and powerlessness vis-à-vis white students and staff (Erasmus \& De Wet, 2003/2011), thus expressing distinct unequal status of the groups. Such manifestations of inequality and power asymmetries are probably not limited to formerly segregated countries, but might also be persistent during some intergroup contact situations within Germany between majority and minority members. For example, people with a migration background in Germany report that physical characteristics that differentiate them from "autochthone" Germans lead to a lack of acceptance, indicating that parts of the population stick to an essentialist 
conception of belongingness which implies unequal status (Holtz et al., 2013). In such contexts of deficits in societal acceptance, it might be particularly important that intergroup contact situations are characterized by direct interactions on an equal footing.

Contact can improve intergroup attitudes via various routes, including the perception of intergroup similarities and a re-definition of intergroup boundaries. In case of the so-called "recategorisation" approach, it is attempted to foster identification with a superordinate group, which comprises former ingroup and outgroup members under the umbrella of a common group, possibly fostered by working on a joint goal (Brown, 2002; Gaertner et al., 1993). Extending the group boundaries, so that former outgroup members become ingroup members, entails that the consequences of ingroup assimilation and liking are also applied to these former outgroup members (Dovidio et al., 2007). Thus, the awareness of a superordinate and common group identification is a possible route to improve intergroup relationships. More generally, intergroup contact appears to entail the potential to modify members' understanding of intergroup relations.

\section{The Present Study}

Due to this potential of changing the view on intergroup relations, it is hypothesized in the present study that intergroup contact modifies the relationship between national identification and xenophobia. For both West and East Germany, it has been demonstrated that national identification is associated with prejudice towards immigrants (Pehrson et al., 2009). The association between national identification and prejudice seems to be stronger amongst countries defining national community "ethnically" (or possibly culturally), instead of based on citizenship (Pehrson et al., 2009, 2011). Thus, these results suggest that more ethnically charged definitions of national communities may emphasize intergroup differences. Intergroup differences, in turn, are associated with outgroup devaluations, to the degree that the outgroup (prototype) is perceived to be different from the ideal self (Turner, 1987). Therefore, identifying with a country whose citizenry is defined "ethnically" exclusive is likely to be associated with contrasting the own group towards other groups perceived to be ethnically different, which can imply a devaluation of outgroups. In contrast, if the definition of the national group is wide enough to include diverse groups, immigrants from other backgrounds are possibly perceived as part of the national ingroup. Based on previous results (Pehrson et al., 2009, 2011) and on the assumption that national belonging in Germany is related to the concept of "ethnicity", we hypothesized that we could replicate the association between national identification and xenophobia in Germany (H1).

"Ethnicity" should not be regarded in essentialist terms, in the sense of a naturally given category that pre-defines fixed boundaries between individuals, since the borders between ethnicities and their definitional content have developed in social interactions instead of being predetermined by innate differences (see Brubaker, 2004). Thus, whilst the capacity of social categorizations is fundamental to human cognition, emotion, and action (Turner, 1987), the concept of ethnicity is historically and culturally bound. At the same time, the consequences of classifying people 
into ethnicities on thinking, feeling, and acting are tangible when this classification is shared by a large number of people (see Brubaker, 2004). To the degree that the view on the national group is modifiable from an ethnically exclusive to an inclusive understanding of the national self, the association between national identification and xenophobia could also be changed.

It has been indicated that contact can transform intergroup relations by redefining intergroup boundaries. Additionally, positive effects of intergroup contact are mediated by increased knowledge about the outgroup and by empathy (Pettigrew \& Tropp, 2008). These mediators are likely to change the content of the group categorizations and thereby possibly their inclusiveness. In the context of the present analysis, it was therefore hypothesized that intergroup contact changes the association between national identification and xenophobia. More precisely, it was hypothesized that the effect of national identification on xenophobia would be moderated by contact (H2).

It was also expected that "ethnic" identification has a main effect on xenophobia (H3), as a high identification with such an "ethnically" exclusive group should render the differences to other "ethnicities" more salient. To the extent that these other groups are perceived to be deviating from the ideal self, a high ethnic identification should entail devaluation of other "ethnic" groups. Additionally, it was expected that outgroup contact moderates this effect (H4). Although the borders of an ethnic identification cannot easily be withdrawn to include other "ethnicities" without undermining the basis of the categorization, the content of the categories and the relationship between the groups can still be changed. In particular, contact can foster knowledge about the outgroup and empathy (Pettigrew \& Tropp, 2008). Increased background knowledge of the outgroup's values and empathy with their situation, in turn, could induce that the effect of ethnic identification on xenophobia is buffered.

\section{Method}

\section{Procedure}

The participants of the study were recruited by snowball sampling, starting with personal acquaintances, thus constituting a convenience sample. The participants completed a printed questionnaire. Prior to participation, they were informed about voluntariness and anonymity, and that data were used only for scientific purposes, according to the agreement with the ethics committee of the University of Applied Sciences Osnabrück. Following the information, participants gave their informed consent on the participation.

\section{Measures}

Demographic Variables Participants were asked for demographic information, such as age, gender, formal education, size of the municipality of residence, country of 
residence, citizenship, and mother tongue. Age, gender, and education served as control variables in the main analyses of this study.

National Identification To measure national identification, five items were used from an adapted version of the scale of social identity by Orth et al., (1996; e.g. "I feel German") with a 7-point Likert scale from 1 (not true at all) to 7 (completely true). Cronbach's $\alpha$ was very good, reaching 0.91 .

Ethnic Identification To assess ethnic identification, a subscale of the Multigroup Ethnic Identity Measures (MEIM; Phinney, 1992) was employed, namely "affirmation and belonging". This subscale consists of five items and targets emotional aspects of identification (e.g. "I have a strong sense of belonging to my own ethnic group" or "I am happy that I am a member of the group I belong to") and was translated to German. The response scale was a 5-point Likert scale, ranging from 1 (strong rejection) to 5 (high approval). Cronbach's $\alpha$ of this scale was good: 0.83 .

Contact Contact with people with a migration background was surveyed using the following four items of the MEIM (Phinney, 1992): "I enjoy meeting and getting to know people from other ethnic groups", "I often spend time with people from other ethnic groups", "I do not try to participate in activities with people from other ethnic groups" (reversed item), and "I am involved in activities with people from other ethnic groups". These items were translated to German. The response scale was a 5 -point Likert scale, ranging from 1 (strong rejection) to 5 (high approval). Cronbach's $\alpha$ of this scale was 0.82 .

Xenophobia Xenophobic attitudes were measured on the basis of nine items, which constitute a shortened version of the scale from the survey instrument for student interviews conducted by the Criminological Research Institute of Lower Saxony by Wetzels et al. (1998), using a 4-point Likert scale from 0 (not true at all) to 3 (completely true). An example item of the scale is "Those who cannot adapt in Germany should leave the country". Cronbach's $\alpha$ was 0.82 .

\section{Sample}

A total of 100 respondents took part in the survey, $49 \%$ of whom were female. On average, the participants were 38 years old $(S D=12.00)$. Thirty-six percent had a low educational qualification, $43 \%$ had at least a medium qualification ("Mittlerer Reife"/about GCSE or "Abitur"/about A level), and 21\% had a university or college degree. Twelve percent were living in a large city (above 100,000 inhabitants), $24 \%$ lived in a small city or town, while $64 \%$ lived in a village. All participants were born in Germany, had German citizenship, and had German as their mother tongue. 
Table 1 Means, standard deviations, and intercorrelations for the variables

\begin{tabular}{|c|c|c|c|c|c|c|c|c|}
\hline Measure & $M$ & $S D$ & 2 & 3 & 4 & 5 & 6 & 7 \\
\hline 1. Age & 38.10 & 12.18 & 0.18 & -0.13 & 0.09 & 0.08 & -0.09 & 0.11 \\
\hline 2. Gender & & & & -0.08 & 0.01 & 0.06 & -0.19 & 0.04 \\
\hline 3. Education & & & & & $-0.21^{*}$ & -0.06 & $0.44^{* * *}$ & $-0.57^{* * *}$ \\
\hline 4. National identification & 5.37 & 1.23 & & & & $0.59^{* * *}$ & $-0.30^{* *}$ & $0.34^{* * *}$ \\
\hline 5. Ethnic identification & 3.85 & 0.72 & & & & & -0.08 & $0.25^{*}$ \\
\hline 6. Contact & 3.13 & 0.90 & & & & & & $-0.58^{* * *}$ \\
\hline 7. Xenophobia & 1.08 & 0.52 & & & & & & \\
\hline
\end{tabular}

Note. Higher mean scores indicate a higher level of the construct in question. The coding for gender was 0-female; 1-male; for education: 0-no university/college degree; 1-university or college degree. The scores for the national identification could range from 1 to 7 , ethnic identification and contact could range from 1 to 5, and xenophobia could range from 0 to 3. Owing to missing values, $n$ s varied between 97 and 100

$* p \leq 0.05 ; * * p \leq 0.01 ; * * * p \leq 0.001$ (all two-tailed)

\section{Results}

Means, standard deviations, and correlations of the variables used in the analyses are presented in Table 1.

As displayed in Table 1, national and ethnic identification correlated by 0.59 , indicating that the two concepts are associated with one another, while also having substantial unique shares of variance. We also tested by a main component analysis whether the items of the national identification measure and those of the ethnic identification measure are statistically distinguishable. Applying the Kaiser-GuttmanCriterion (i.e. eigenvalues $>1$ ), the main component analysis yielded indeed two components, together explaining $68.99 \%$ of the variance. The item loadings suggested assignments of items that precisely corresponded to the distinction between ethnic identification and national identification. After varimax rotation, the items of the national identification scale had loadings between 0.71 and 0.90 on the first component, while the items of the ethnic identification scale had loadings between 0.59 and 0.82 on the second component.

A multiple regression analysis was employed to test whether contact moderates the relationship between national identification and xenophobia, using the product term of national identification and contact as the main predictor. National identification and contact were included as further predictors, while age, gender, and education (no university/college degree vs. university/college degree) served as control variables. We centred both national identification and contact prior to computing the product term and included the variables into the regression analysis, since centring variables which are part of the interaction enables a more meaningful interpretation of their main effects.

The regression analysis reached a high coefficient of determination $(R=0.720$, $\left.R^{2}=0.518, R_{\text {adj }}^{2}=0.486, F(6,90)=16.127, p<0.001\right)$. As expected, a positive effect for national identification on xenophobia was found $(b=0.094, S E=0.035$, $\beta=0.218, t=2.69, p=0.008)$. Additionally, there was a negative effect of contact on 
Fig. 1 Simple slopes for the interaction effect of national identification and contact

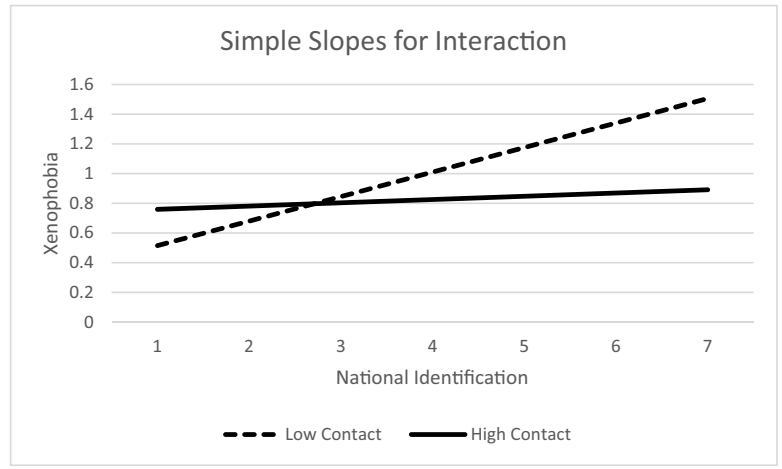

xenophobia $(b=-0.213, S E=0.050, \beta=-0.368, t=-4.30, p<0.001)$. The only significant control variable was education $(b=-0.457, S E=0.104, \beta=-0.363$, $t=-4.01, p<0.001)$. Furthermore, the anticipated interaction effect between national identification and contact emerged as expected $(b=-0.080, S E=0.035$, $\beta=-0.173, t=-2.60, p=0.026)$. In order to examine the significance of the simple slopes, the SPSS Macro Process (Hayes, 2017) was used. Simple slopes indicated that national identification had an effect on xenophobia when contact was below its mean or close to its mean, but not when contact was above its mean. (for contact 1 $S D$ below average: $b=0.165, S E=0.053 t=3.09, p=0.003$; for contact at average, see the main effect; for contact $1 S D$ above average: $b=0.022, S E=0.040, t=0.56$, $p=0.580$ ). In other words, national identification is only associated with xenophobia when contact has average or below average values, but not when contact is high, indicating that contact can neutralize the detrimental effect of national identification. For depicting the simple slopes, values of xenophobia were computed, using the full regression equation and entering varying values for national identification and contact into the equation. Figure 1 presents the simple slopes of xenophobia as a function of national identification when contact is $1 S D$ below versus $1 S D$ above contact's mean. (For the computation underlying this figure, the mean values for the control variables were entered into the regression equation, which determine the intercepts displayed in the figure.)

To test the robustness of this interaction, we repeated the analysis with another measure for contact. Since the original measure included items that could be interpreted as motivational aspects of contact, we also used a contact measure which only employed the items "I often spend time with people from other ethnic groups" and "I am involved in activities with people from other ethnic groups". When repeating the multiple regression analysis above, using the same variables except for replacing the original contact variable by the two-item variable, the expected interaction effect could still be observed $(b=-0.091, S E=0.035, \beta=-0.210, t=-2.72, p=0.008)$.

To test the effect of ethnic identification on xenophobia, another regression analysis was specified. The same variables as in the first regression analysis were entered, except that ethnic identification was substituted for national identification. Both ethnic identification and contact were centred prior to computing the interaction term and running the regression analysis, while age, gender, and education served as 
control variables $\left(R=0.716, R^{2}=0.512, R_{\text {adj }}^{2}=0.480, F(6,90)=15.766, p<0.001\right)$. As anticipated, a positive effect for ethnic identification was found $(b=0.142$, $S E=0.054, \beta=0.195, t=2.64, p=0.010)$. Additionally, a negative effect of contact $(b=-0.234, S E=0.049, \beta=-0.403, t=-4.78, p<0.001)$ and of education were again observed $(b=-0.484, S E=0.104, \beta=-0.384, t=-4.65, p<0.001)$. There was, however, no significant interaction between ethnic identification and contact $(b=-0.045, S E=0.036, \beta=-0.092, t=-1.23, p=0.222)$.

\section{Discussion}

In line with previous studies and hypothesis 1 , an effect of national identification on xenophobia among majority members in Germany was found (Billiet et al., 2003; Maddens et al., 2000; Masson \& Verkuyten, 1993; Triandafyllidou, 2000; Weiss, 2003). Pehrson et al. (2009) noticed that such an association is more likely in countries which define national belonging by language (which represents an "ethnic" marker) instead of citizenship. Matching this idea is the observation that German citizenry used to be defined as a community of descent instead of a territorial community (Brubaker, 1990).

However, Brubaker (2004, drawing on Smith, 1986) also indicates that "common descent" can have different meanings, being either interpreted in strictly "biological" (blood) terms or in terms of a shared ideology. Further differentiations of the societal understanding of national belongingness in Germany are indicated by MillerIdriss (2006), who found that different generations in Germany vary in the extent to which they define being German based on descent or cultural criteria (Miller-Idriss, 2006).

Irrespective of whether biological descent or cultural characteristics are assumed as the criteria for being German, immigrants from nations that have limited commonalities in terms of descent or culture with Germany can easily be regarded as different in the eyes of those who have an inclination to categorize people on the basis of nations. Identifying with Germany can thus be closely associated with identifying with an exclusive group, while differences to other groups might be constructed and become linked to the concept of "ethnicity". Consequently, a high national identification can render differences to other national or "ethnic" groups salient. Viewing other "ethnic" groups as deviating from an ingroup and seeing the ingroup as being more closely related to the ideal self can entail devaluation of the outgroup through the salience of intergroup differences (Turner, 1987).

We also found that participants distinguished between identification with Germany and ethnic identification. These measures were related $(r=0.59, p<0.001)$, suggesting that the concept of being German is related to an "ethnic" concept. In addition to this hint of conceptual overlap, our analyses indicated that participants partially attribute unique meanings to these concepts, as a main component analysis suggested a two-component solution and yielded loadings that were in accordance with the assignment of the items to the two original scales. Also, the fact that only one of the identification measures was moderated by intergroup contact suggests that participants differentiated between these identifications. 
Most importantly, the results corroborate the expected moderation of the effect of national identification on xenophobia by intergroup contact. Accordingly, national identification and xenophobia only display a significant positive association when people have below-average or close to average contact with ethnic outgroups. In contrast, above-average contact between members of the majority and members of ethnic outgroups erases the statistical significance of the link between national identification and xenophobia. One possible explanation for the absence of a significant association between national identification and xenophobia among participants with a lot of intergroup contact is that for these people, national identification has already widened to be more inclusive. National identification might therefore, for these participants, accommodate individuals from other ethnic groups (see Bauer \& Hannover, 2020; Gaertner et al., 1993). Additionally, contact might also have increased participants' knowledge about the outgroup and/or their perspective-taking and empathy (Pettigrew \& Tropp, 2008). Thus, it is conceivable that the buffering effect of contact is not (or not only) an outcome of modified group boundaries, but (also) of a changed view of outgroups. According to this possible influence, the content of the outgroup categories could be changed, leading to less devaluation, without necessarily changing the view of the ingroup and its boundaries.

A relevant supplement to the results on national identification is constituted by the analysis involving ethnic identification. The expected effect of ethnic identification on xenophobia was found, which parallels the effect of national identification. Identification with an ethnic group should render differences to other ethnic groups more salient, so that outgroups are devalued, to the degree that they are seen to differ from appreciated ingroup features or values. Interestingly, this effect of ethnic identification on xenophobia was not significantly moderated by contact, so that in this case there is no indication of contact as a buffer. While an absence of an effect cannot corroborate a null hypothesis, a weaker (non-observable) moderating effect in the case of ethnic identification suggests that national identification is more malleable than ethnic identification.

To the degree that ethnicity is defined as being associated with common descent, it implies an essentialist view of belonging, to the effect that its borders are not regarded as being porous, thus excluding groups perceived as having a different descent. National identification, in contrast, is more open in this respect. Thus, an interpretation of the observed pattern might be that contact can more readily work via widening intergroup boundaries (or alleviating their sharpness) than by changing the perceived differences between the ingroup and outgroups. Additionally, a strong ethnic identification could be a more reliant sign of an exclusionary mindset than national identification. Possibly, identifying strongly with an ethnic group is much more likely when a hierarchical thinking towards ethnicities is present a priori. An identification which is closely intertwined with (or even defined by) the devaluation of other groups would be hard to change by outgroup contact or other experiences. If ethnic identifications were indeed involving the devaluation of other groups, interventions might work better via reducing this identification than via changing the content of these identifications.

It is possible that the strength of the interaction between national identification and contact also varies as a function of the form or context of contact (e.g. contacts 
with neighbours vs. with work colleagues vs. with friends; Davies et al., 2011). It would be plausible, for example that more intimate types of contact with outgroup members precipitate greater effects. Such a differential effect is in line with the suggestion of Pettigrew (1997) that an essential condition of intergroup contact is their potential to create friendships. In line with this, Davies and colleagues (Davies et al., 2011) demonstrated that the time and activities shared with friends from an outgroup are more important in reducing prejudices than the number of friends from this outgroup. Future studies should therefore examine the type of contact with people with a migration background in a more differentiated way in order to gather more information on intergroup contact and xenophobia.

\section{Limitations}

A central limitation of this study is its cross-sectional design. It has been demonstrated previously that contact with people with a migration background has a negative effect on prejudice, while an effect of prejudice on contact has also been demonstrated (Binder et al., 2009). Especially the question of mediators would deserve further study. Therefore, future research on the interrelationship between identification, contact with outgroups, perceived content of group categories, and xenophobia ought to aim for longitudinal designs which include these variables and possible mediators to move closer to causal analysis.

A further limitation concerns the measurement of xenophobia in this study. The employed scale of Wetzels et al. (1998) includes items which assess the approval of a "strong leader" and the subjective importance of "quiet and order", implying that the construct measured by the scale could be a broader syndrome of right-extremism, instead of xenophobia in a narrower sense. Although the scale achieved a good internal consistency in our study, future studies might profit from using additional, possibly narrower scales for the measurement of xenophobia.

\section{Conclusion}

This study demonstrates that contact between members of the majority population and people with a migration background is significant with regard to the nature of the connection between national identification and xenophobia. It was observed that above-average contact with members of outgroups eliminated the significant positive association between national identification and xenophobia. Thus, the findings of the present study go beyond the contact hypothesis (Allport, 1954) and its observed effects (Pettigrew and Tropp, 2006, 2008), as they demonstrate that a detrimental effect of national identification can be neutralized by intergroup contact. The findings also suggest the potential value of initiatives to support meetings between majority members and immigrants in Germany, such as those endeavoured by the federal government in the context of the federal programme "Live Democracy!" ("Demokratie leben"; Bundesministerium für Familie, Senioren, Frauen und Jugend, 2020). For contact initiatives likes these, it is important that the precise mechanisms 
which can reduce prejudice and improve intergroup relations are better understood. The current research on the mitigating effect of contact on national identification delivers a hint, which should be viewed in the light of previous research on the mechanism of the reduction of prejudice (Pettigrew \& Tropp, 2006, 2008). Mediators which contribute to the reduction of prejudice, such as perspective-taking and the reduction of perceived threats, could work best in a certain sequence of experiences. Another potential route for the reduction of prejudice is indicated by the present study. The buffering effect of contact observed in this study could be based on a modified conceptualization of the national group. When national belonging becomes detached from an exclusionist view of the nation, room is opened for societal conception that can accommodate groups from other nations or cultures. Future research should investigate by which mechanisms the contact effects and, potentially, a redefinition of the national ingroup can be explained.

The readiness to include others in the national ingroup could be facilitated when intergroup commonalities are discovered in exchanges with people with a migration background. Effects of contact, such as the reduction of fears and the fostering of empathy and perspective-taking (Pettigrew \& Tropp, 2008), are likely to facilitate communicative exchanges. The discovery of intergroup commonalities through communication, in turn, should render the redefinition of the ingroup more likely and change intergroup boundaries (Gaertner et al., 1993). ${ }^{1}$

Bringing internal heterogeneities of groups to the foreground can constitute a further building block for modifying intergroup boundaries. The salience of internal heterogeneity of the national ingroup could change its inclusiveness. Emphasizing the heterogeneity of the ingroup in combination with a focus on commonalities with immigrants could contribute to a concept of the national group which is not bound

\footnotetext{
1 In addition to personal contact experiences, media play a central role in the conceptual construction of nations and intergroup relations, as they are major channels which impart portrayals and representations of societal groups. Mainstream media in Germany partially contribute to the consolidation of intergroup boundaries and exclusion. For example, people with migration background are often represented in negative ways, with a focus on foreign aspects and on criminals (Christoph, 2012; Wigger, 2019), thus inhibiting the acceptance of integration (Wigger, 2019). Contrasting with this tendency towards negative representations are media portrayals which imply the inclusion of people with migration background in the conception of Germany. Zambon (2017), for example has analyzed television productions that feature families with a migration background which are well-established in German society. These productions depict cultural and human commonalities between these families and mainstream German culture, but also cultural differences, while unity is still uphold despite these differences. Additionally, these productions portray some heterogeneity within cultural groups (Zambon, 2017).

Further initiatives attempt to promote the acceptance of pluralism in Germany, like, for example the employers' initiative "Charta of Diversity" (Charta der Vielfalt, 2021). This initiative aims to promote the recognition and inclusion of diversity in organization, by trying to value all employers and to create a space free of prejudice. Similarly, some organizations have implemented measures to increase diversity. For example, one large company attempts to reduce (formerly) unconscious biases in recruitment processes by workshops which aim to increase sensitivities of HR specialists and managers to stereotypes and prejudice (Wagner, 2021). Other initiatives aim at the integration of immigrants via, for example women's groups, tutoring offers, or language mediators. An example of a regional initiative of this type supports volunteers by offering trainings on intercultural competence, diversity, interreligious awareness, strategies of argumentation, anti-discrimination and activities against right-wing attitudes (Evangelisches Werk für Diakonie und Entwicklung, 2021).
} 
to essentialist cultural or ethnic ideas and allows for the inclusion of people with various backgrounds.

The precise empirical interrelationships of the potential mechanisms for the reduction of prejudice is a subject for future research. The present study has underlined the importance for research on intergroup contact in the domain of national identification, by indicating that detrimental effects of identification should not be regarded as automatisms. Instead, a pluralistic conceptualization of national identification could enable the coexistence of national identification and the accommodation of groups from various nations and cultures.

Author contribution Petia Genkova conceptualized the study and its design. Petia Genkova also prepared the material. Simone Karch collected the data. Christoph Daniel Schaefer performed the data analysis and wrote the original and revised draft of the manuscript. All authors read and approved the final manuscript.

Funding Open Access funding enabled and organized by Projekt DEAL.

Availability of Data and Material Due to data protection requirements and the assurances given to participants, our research data should only be published on the aggregate level instead of the level of individuals. However, we are happy to respond to requests from readers.

Code Availability Not applicable.

\section{Declarations}

Ethics Approval For this study, no formal approval by an ethics committee was required. There was no deception of the participants involved, neither were participants exposed to stressful situations.

Consent to Participate Participants were informed about the anonymity and the voluntariness of the study prior to the start of the survey. They were informed that, for purely scientific purposes, the data could be processed anonymously. Participants were also informed that aborting their participation would not result in any disadvantages for them. They were then asked for their informed consent.

Consent for Publication By default, participants implicitly agreed to anonymous publication of data aggregated across participants.

Competing Interests The authors declare no competing interests.

Open Access This article is licensed under a Creative Commons Attribution 4.0 International License, which permits use, sharing, adaptation, distribution and reproduction in any medium or format, as long as you give appropriate credit to the original author(s) and the source, provide a link to the Creative Commons licence, and indicate if changes were made. The images or other third party material in this article are included in the article's Creative Commons licence, unless indicated otherwise in a credit line to the material. If material is not included in the article's Creative Commons licence and your intended use is not permitted by statutory regulation or exceeds the permitted use, you will need to obtain permission directly from the copyright holder. To view a copy of this licence, visit http://creativecommons.org/licen ses/by/4.0/. 


\section{References}

Allport, G. W. (1954). The nature of prejudice. Addison Wesley.

Bauer, C. A., \& Hannover, B. (2020). Changing "us" and hostility towards "them"- Implicit theories of national identity determine prejudice and participation rates in an anti-immigrant petition. European Journal of Social Psychology, 50(4), 810-826. https://doi.org/10.1002/ejsp.2666.

Billiet, J., Maddens, B., \& Beerten, R. (2003). National identity and attitude toward foreigners in a multinational state: A replication. Political Psychology, 24(2), 241-257. https://doi.org/10.1111/ 0162-895X.00327.

Binder, J., Zagefka, H., Brown, R., Funke, F., Kessler, T., Mummendey, A., Maquil, A., Demoulin, S., \& Leyens, J.-P. (2009). Does contact reduce prejudice or does prejudice reduce contact? A longitudinal test of the contact hypothesis among majority and minority groups in three European countries. Journal of Personality and Social Psychology, 96, 843-856. https://doi.org/10.1037/ a0013470.

Brown, R. (2002). Beziehungen zwischen Gruppen. [Relationships between groups.] In W. Stroebe, K. Jonas, K. Hewstone, \& M. Hewstone (eds.), Sozialpsychologie: Eine Einführung (pp. 537-576). Springer.

Brubaker, W. R. (1990). Immigration, citizenship, and the nation-state in France and Germany: A comparative historical analysis. International Sociology, 5, 379-407. https://doi.org/10.1177/02685 8090005004003.

Brubaker, R. (2004). Ethnicity without groups. Harvard University Press.

Bundesamt für Migration und Flüchtlinge (2020). Partnerschaften für Demokratie. Bundesamt für Migration und Flüchtlinge.

Charta der Vielfalt (2021). Social Media-Aktion zum \#DDT21 [Social Media Campaign for the Day of German Diversity 2021]. Berlin, Germany: Charta der Vielfalt e. V. https://www.charta-der-vielfalt. de/fileadmin/user_upload/Diversity-Tag/2021/DDT21_Handout_Social_Media_Aktion__DDT21. pdf.

Christoph, V. (2012). The role of the mass media in the integration of migrants. Mind, Brain, and Education, 6(2), 97-107. https://doi.org/10.1111/j.1751-228X.2012.01142.x.

Davies, K., Tropp, L. R., Aron, A., Pettigrew, T. F., \& Wright, S. C. (2011). Cross-Group Friendships and Intergroup Attitudes: A Meta-Analytic Review. Personality and Social Psychology Review, 15(4), 332-351. https://doi.org/10.1177/1088868311411103.

Decker, O., Brähler, E., Baier, D., \& Bergmann, M. C. (2018). Flucht ins Autoritäre: Rechtsextreme Dynamiken in der Mitte der Gesellschaft: die Leipziger Autoritarismus-Studie 2018. [Escape into the authoritarian: Right-wing extremist dynamics in the middle of society: The Leipzig Authoritarianism Study 2018.] Psychosozial-Verlag.

Dovidio, J. F., Gaertner, S. L., \& Saguy, T. (2007). Another view of "we": Majority and Minority group perspectives on a common ingroup identity. European Review of Social Psychology, 18, 296-330. https://doi.org/10.1080/10463280701726132.

Durrheim, K., \& Dixon, J. (2005). Studying talk and embodied practices: Toward a psychology of materiality of 'race relations.' Journal of Community \& Applied Social Psychology, 15, 446-460. https:// doi.org/10.1002/casp.839.

Erasmus, Z. (2010). Contact theory: Too timid for "race" and racism. Journal of Social Issues, 66(2), 387-400. https://doi.org/10.1111/j.1540-4560.2010.01651.x.

Erasmus, Z., \& De Wet, J. (2003/2011). Not naming race: some medical students' perceptions and experiences of 'race' and racism at the Health Sciences Faculty of the University of Cape Town. Cape Town, South Africa: University of Cape Town. http://hdl.handle.net/11427/7571.

Evangelisches Werk für Diakonie und Entwicklung (2021). ELIA - Ehrenamt leben im Alltag [Volunteering in everyday life]. Retrieved from https://www.diakonie-kennenlernen.de/projekt/elia-ehren amt-leben-im-alltag/.

Gaertner, S. L., Dovidio, J. F., Anastasio, P. A., Bachman, B. A., \& Rust, M. C. (1993). The common ingroup identity model: Recategorization and the reduction of intergroup bias. European Review of Social Psychology, 4(1), 1-26. https://doi.org/10.1080/14792779343000004.

Hayes, A. F. (2017). Introduction to mediation, moderation, and conditional process analysis: A regression-based approach. Guilford publications. 
Holtz, P., Dahinden, J., \& Wagner, W. (2013). German Muslims and the "integration debate": Negotiating identities in the face of discrimination. Integrative Psychological and Behavioral Science, 47(2), 231-248. https://doi.org/10.1007/s12124-012-9227-6.

Maddens, B., Billiet, J., \& Beerten, R. (2000). National identity and the attitude towards foreigners in multi-national states: The case of Belgium. Journal of Ethnic and Migration Studies, 26(1), 45-60. https://doi.org/10.1080/136918300115633.

Martinovic, B., \& Verkuyten, M. (2012). Host national and religious identification among Turkish Muslims in Western Europe: The role of ingroup norms, perceived discrimination and value incompatibility. European Journal of Social Psychology, 42, 893-903. https://doi.org/10.1002/ejsp.1900.

Masson, C. N., \& Verkuyten, M. (1993). Prejudice, ethnic identity, contact and ethnic group preferences among Dutch young adolescents. Journal of Applied Social Psychology, 23(2), 156-168. https://doi. org/10.1111/j.1559-1816.1993.tb01058.x.

Miller-Idriss, C. (2006). Everyday understandings of citizenship in Germany. Citizenship Studies, 10(5), 541-570. https://doi.org/10.1080/13621020600954978.

Orth, B., Broszkiewicz, A. \& Schütte, A. (1996). Skalen zur sozialen Identität, EigengruppenFavorisierung und Ego-Stereotypisierung. [Scales for social identity, ingroup favouritism, and egostereotyping.] Zeitschrift für Differentielle und Diagnostische Psychologie, 17, 262-267.

Pehrson, S., Vignoles, V. L., \& Brown, R. (2009). National identification and anti-immigrant prejudice: Individual and contextual effects of national definitions. Social Psychology Quarterly, 72(1), 24-38. https://doi.org/10.1177/019027250907200104.

Pehrson, S., Brown, R., \& Zagefka, H. (2011). When does national identification lead to the rejection of immigrants? Cross-sectional and longitudinal evidence for the role of essentialist in-group definitions. British Journal of Social Psychology, 48, 61-76. https://doi.org/10.1348/014466608X288827.

Pettigrew, T. F. (1997). Generalized Intergroup Contact Effects on Prejudice. Personality and Social Psychology Bulletin, 23(2), 173-185. https://doi.org/10.1177/0146167297232006.

Pettigrew, T. F., \& Tropp, L. R. (2006). A meta-analytic test of intergroup contact theory. Journal of Personality and Social Psychology, 90(5), 751-783. https://doi.org/10.1037/0022-3514.90.5.751.

Pettigrew, T. F., \& Tropp, L. R. (2008). How does intergroup contact reduce prejudice? Meta-analytic tests of three mediators. European Journal of Social Psychology, 38(6), 922-934. https://doi.org/10. 1002/ejsp.504.

Phinney, J. S. (1992). The multigroup ethnic identity measure: A new scale for use with diverse groups. Journal of Adolescent Research, 7(2), 156-176. https://doi.org/10.1177/074355489272003.

Schaefer, C. D., \& Simon, B. (2017). Opportunities for immigrants' acculturation and identification varieties. Political Psychology, 38(6), 959-975. https://doi.org/10.1111/pops.12381.

Smith, A. D. (1986). The Ethnic Origins of Nations. Basil Blackwell.

Statistisches Bundesamt. (2020). Bevölkerung mit Migrationshintergrund: Ergebnisse des Mikrozensus 2019 [Population with immigration background: Results of the microcensus 2019]. Wiesbaden: Statistisches Bundesamt. Retrieved from https://www.destatis.de/DE/Themen/Gesellschaft-Umwelt/ Bevoelkerung/Migration-Integration/Publikationen/Downloads-Migration/migrationshintergrund2010220197004.html.

Stephan, W. S., \& Stephan, C. W. (2013). An integrated threat theory of prejudice. In S. Oskamp (Ed.), Reducing prejudice and discrimination (pp. 33-56). Psychology Press.

Suleman, S., Garber, K. D., \& Rutkow, L. (2018). Xenophobia as a determinant of health: An integrative review. Journal of Public Health Policy, 39, 407-423. https://doi.org/10.1057/s41271-018-0140-1.

Tajfel, H., \& Turner, J. C. (1979). An integrative theory of intergroup conflict. In W. G. Austin \& S. Worchel (eds.), Organizational identity: A reader, 56, 33-47.

Triandafyllidou, A. (2000). The political discourse on immigration in southern Europe: A critical analysis. Journal of Community \& Applied Social Psychology, 10(5), 373-389. https://doi.org/10.1002/ 1099-1298(200009/10)10:5\%3c373::AID-CASP595\%3e3.0.CO;2-R.

Turner, J. C. (1987). Rediscovering the Social Group: A Self-Categorization Theory. Basil Blackwell.

Wagner, J. (2021). Vielfalt gewinnt [diversity succeeds]. Retrieved from https://www.deutschland.de/de/ topic/leben/diversity-vielfalt-in-unternehmen.

Weiss, H. (2003). A cross-national comparison of nationalism in Austria, the Czech and Slovac Republics, Hungary, and Poland. Political Psychology, 24(2), 377-401. https://doi.org/10.1111/0162895X.00332. 
Wetzels P., Enzmann D., Mecklenburg E. \& Pfeiffer C. (1998). Gewalterfahrungen und Kriminalitätsfurcht von Schülerinnen und Schülern in Stuttgart. Kriminologisches Forschungsinstitut Niedersachen.

Wigger, I. (2019). Anti-Muslim racism and the racialisation of sexual violence: 'intersectional stereotyping' in mass media representations of male Muslim migrants in Germany. Culture and Religion, 20(3), 248-271. https://doi.org/10.1080/14755610.2019.1658609.

Zambon, K. (2017). Negotiating new German identities: Transcultural comedy and the construction of pluralistic unity. Media, Culture \& Society, 39(4), 552-567. https://doi.org/10.1177/0163443716 663640 .

Publisher's Note Springer Nature remains neutral with regard to jurisdictional claims in published maps and institutional affiliations. 